\title{
High correlation between genotypes and phenotypes of environmental bacteria Comamonas testosteroni strains
}

\author{
Lin Liu, Wentao Zhu, Zhan Cao, Biao Xu, Gejiao Wang ${ }^{*}$ and Meizhong Luo*
}

\begin{abstract}
Background: Members of Comamonas testosteroni are environmental microorganisms that are usually found in polluted environment samples. They utilize steroids and aromatic compounds but rarely sugars, and show resistance to multiple heavy metals and multiple drugs. However, comprehensive genomic analysis among the $C$. testosteroni strains is lacked.

Results: To understand the genome bases of the features of $C$. testosteroni, we sequenced 10 strains of this species and analyzed them together with other related published genome sequences. The results revealed that: 1$)$ the strains of $C$. testosteroni have genome sizes ranging from 5.1 to $6.0 \mathrm{Mb}$ and $\mathrm{G}+\mathrm{C}$ contents ranging from $61.1 \%$ to $61.8 \%$. The pan-genome contained 10,165 gene families and the core genome contained 3,599 gene families. Heap's law analysis indicated that the pan-genome of $C$. testosteroni may be open $(a=0.639) ; 2)$ by analyzing 31 phenotypes of 11 available C. testosteroni strains, $99.4 \%$ of the genotypes (putative genes) were found to be correlated to the phenotypes, indicating a high correlation between phenotypes and genotypes; 3) gene clusters for nitrate reduction, steroids degradation and metal and multi-drug resistance were found and were highly conserved among all the genomes of this species; 4) the genome similarity of $C$. testosteroni may be related to the geographical distances.
\end{abstract}

Conclusions: This work provided an overview on the genomes of C. testosteroni and new genome resources that would accelerate the further investigations of this species. Importantly, this work focused on the analysis of potential genetic determinants for the typical characters and found high correlation between the phenotypes and their corresponding genotypes.

Keywords: Comamonas testosteroni, Comparative genomics, Genotype, Phenotype

\section{Background}

Comamonas testosteroni is a bacterial species belonging to $\beta$-Proteobacteria which was originally named as Pseudomonas testosteroni using a soil bacterium ATCC 11996 as the type strain [1]. In 1987, Tamaoka et al. reclassified this species into Comamonas testosteroni based on phylogenetic analysis [2]. C. testosteroni strains are capable of utilizing testosterone, 4-hydroxybenzoate (4HBA), acetate and lactate as their sole carbon sources, but not glucose and most of the carbohydrates [3]. They are strictly aerobic,

\footnotetext{
*Correspondence: mzluo@mail.hzau.edu.cn; gejiao@mail.hzau.edu.cn State Key Laboratory of Agricultural Microbiology and College of Life Science and Technology, Huazhong Agricultural University, Wuhan, Hubei 430070, People's Republic of China
}

highly motile and gram-negative rods and can perform nitrate reduction but cannot denitrify [3].

C. testosteroni strains have been paid a great attention duo to their characteristics of degradation for pollutants and resistance to heavy metals. For example, most strains of $C$. testosteroni were isolated from such environments as active sludge $[4,5]$ and heavy metalcontaminated mining soil [6]; C. testosteroni T-2 could utilize 4-toluenesulphonic acid and 4-sulphobenzoic acid [7]; C. testosteroni SPB-2 (KF-1) could utilize 4sulfophenylcarboxylates [8]. C. testosteroni CNB-1 have successfully been applied in environment bioremediation to degrade 4-chloronitrobenzene $(4 \mathrm{CNB})$ in the soil [9].

The genetic determinants for the organic compound degradation and heavy metal resistance have been analyzed 
in several C. testosteroni strains. Horinouchi et al. discovered five gene clusters for steroid degradation in the genome of C. testosteroni TA441 [10-15]. Gene operons responsible for degrading isophthalate and terephthalate to protocatechuate were determined in C. testosteroni YZW$\mathrm{D}$ by Wang et al. [16]. The operon aph (KLMNOPQB) that encodes phenol hydroxylase and catechol 2,3-dioxygenase, and the operon aph (CEFGHJI) that encodes the enzymes for degrading 2-hydroxymuconic semialdehyde to TCA cycle intermediates were found in C. testosteroni TA441 [17,18]. A gene cluster for protocatechuate (PCA) 4,5-cleavage pathway, which is an important pathway for aromatic compounds, such as 4HBA degradation [19], were found in the genome of $C$. testosteroni CNB-2 [20]. C. testosteroni CNB-1 showed resistance to arsenate and an ars (RPBC) operon was found on the pCNB1 plasmid [5,21]. Xiong et al. [6] have reported ZntA genes responsible for $\mathrm{Zn}$ resistance in C. testosteroni S44.

So far, the genomic sequences of four $C$. testosteroni strains have been published. Ma et al. [5] sequenced the whole genome of $C$. testosteroni $\mathrm{CNB}-2$, analyzed its general genome features, and found genes for many functions such as aromatic compound metabolism, transportation system and drug and heavy metal resistance. Gong et al. [22] sequenced the genome of the type strain of C. testosteroni ATCC 11996. Weiss et al. [23] sequenced the genome of strain KF-1, and found genes for degradation of aromatic compounds such as a gene cluster for PCA 4,5cleavage and a gene cluster for isophthalate degradation. In our previous study, a multiple heavy-metal resistant strain named $C$. testosteroni $\mathrm{S} 44$ was isolated and its genome was sequenced [6]. A series of metal-resistant genes and gene clusters for aromatic compound degradation were found in its genome $[6,24]$. Regarding carbohydrates utilization, studies on both genomes of $C$. testosteroni strains CNB-2 and ATCC 11996 showed that the genes encoding hexokinase and glucokinase were missing $[5,22]$. However, a comprehensive genomic analysis among the C. testosteroni strains is lacked.

The objective of this study was to analyze the genetic basis responsible for important biological characters in multiple C. testosteroni strains. Recently, we have identified ten $C$. testosteroni strains from different mining soils [24,25] according to the $16 \mathrm{~S}$ rRNA gene and physiological and biochemical analysis. In order to gain a comprehensive genotypic and phonotypic understanding, we sequenced the ten $C$. testosteroni strains and analyzed them together with the four published $C$. testosteroni genomes $[5,6,22,23]$. This study is a first comparative genomic analysis for $C$. testosteroni strains. The results have revealed information to better understand this bacterial species at genomic level, and importantly, have pointed out potential genetic determinants for the typical characters and high correlation between the phenotypes and their corresponding genotypes (genes).

\section{Methods}

\section{Genome analysis of $C$. testosteroni and related strains}

A total of 14 C. testosteroni strains were used for genomic analysis. Among them, C. testosteroni strains JC8, JC9, JC12, JC13, DF1, DF2, DS1 [25], JL14, JL40 [24] and D4 were isolated from different mining soils in China (Additional file 1: Table S1) and sequenced in this study by Majorbio Biomedical Science and Technology Co. Ltd using Illumina Hiseq2000 and assembled by SOAPdenovo v1.05 [26]. The draft sequences were submitted to GenBank Whole Genome Shotgun (WGS) database [27] and the accession numbers are shown in Table 1. Genome sequences of four other $C$. testoteroni strains, CNB-2 [5], ATCC 11996 [22], KF-1 [23] and S44 [6] (Table 1) were obtained from the NCBI database. Genome sequences of eight strains of the Comamonadaceae family were also obtained from the NCBI database (Additional file 2: Table S2). They are Acidovorax avenae subsp. avenae RS-1 [28], Alicycliphilus denitrificans K601 [29], Delftia acidovorans SPH-1 [8], Polaromonas naphthalenivorans CJ2 [30], Ramlibacter tataouinensis TTB310 [31], Hylemonella gracilis ATCC 19624 [32], Variovorax paradoxus EPS [33], and Verminephrobacter aporrectodeae subsp. tuberculatae At4 [34]. Annotation/re-annotation of all the genome sequences was performed on-line by Prokaryotic Genome Annotation Server (RAST) [35-37]. The annotation results are available at RAST server (http:// rast.nmpdr.org) with user ID: C_t_visitor and password: testosteroni.

\section{Ortholog clustering analysis}

The OrthoMCL package [38] was used to determine the core-genome and unique genes of each genome. All predicted protein sequences were grouped together and compared with each other using blastp of NCBI-blast 2.27 + program [39]. The homologous protein pairs with E-value cutoff $1 \mathrm{e}-5$ and percent of match $\geq 50 \%$ were parsed, and the normalized homologous scores were calculated. We screened the homologous protein pairs by a custom Perl script with percent of identity greater than $50 \%$. Then the proteins were grouped into orthologous families by cluster tool MCL (MCL; Van Dongen 2000; http://micans.org/mcl/), with the inflation value of 1.5 . The unique genes of each genome were identified based on the resultant orthologous families by a custom Perl script. The core-genome sizes were estimated by summing the orthologous families that contained genes from all the selected genomes. The pan-genome sizes were estimated by summing all the orthologous families and the single genes together. Heap's law [40] was used to calculate the constant $\alpha$ in power law regression analysis $n=\kappa N^{a}$ 
Table 1 General features of the genomes of the Comamonas testosteroni strains used in this study

\begin{tabular}{|c|c|c|c|c|c|c|c|}
\hline Strain & Source & Size (Mb) & GC (\%) & No. of ORFs & $\begin{array}{l}\text { Avg. ORF } \\
\text { length (bp) }\end{array}$ & $\begin{array}{l}\text { Coding } \\
\text { density }(\%)\end{array}$ & $\begin{array}{l}\text { Accession number } \\
\text { (reference) }\end{array}$ \\
\hline C. testosteroni JC8 & Coal mine soil & 5.36 & 61.1 & 4,935 & 934 & 86.04 & AWOS00000000 (this study) \\
\hline C. testosteroni JC9 & Coal mine soil & 5.37 & 61.1 & 4,957 & 934 & 86.15 & AWOT00000000 (this study) \\
\hline C. testosteroni JC12 & Coal mine soil & 5.36 & 61.1 & 4,948 & 932 & 86.06 & AWOU00000000 (this study) \\
\hline C. testosteroni JC13 & Coal mine soil & 5.33 & 61.2 & 4,914 & 934 & 86.20 & AWOV00000000 (this study) \\
\hline C. testosteroni JL14 & Sb mine soil & 5.75 & 61.2 & 5,416 & 900 & 84.88 & AWTN00000000 (this study) \\
\hline C. testosteroni JL40 & Sb mine soil & 5.96 & 61.1 & 5,546 & 914 & 85.12 & AWOR00000000 (this study) \\
\hline C. testosteroni D4 & As polluted soil & 5.06 & 61.6 & 4,674 & 938 & 86.62 & AWTQ00000000 (this study) \\
\hline C. testosteroni DS1 & Cu-Fe mine soil & 5.69 & 61.1 & 5,400 & 897 & 85.22 & AWTM00000000 (this study) \\
\hline C. testosteroni DF1 & Fe mine soil & 5.59 & 61.1 & 5,280 & 906 & 85.62 & AWTO00000000 (this study) \\
\hline C. testosteroni DF2 & Fe mine soil & 5.61 & 61.1 & 5,294 & 907 & 85.58 & AWTP00000000 (this study) \\
\hline C. testosteroni S44 & Sb mine soil & 5.53 & 61.4 & 5,147 & 921 & 85.70 & ADVQ01000000 [6] \\
\hline C. testosteroni CNB-2 & Active sludge & 5.37 & 61.4 & 5,011 & 924 & 86.15 & NC_013446 [5] \\
\hline C. testosteroni ATCC 11996 & Soil & 5.41 & 61.5 & 4,998 & 931 & 86.05 & AHIL01000000 [22] \\
\hline C. testosteroni KF-1 & Active sludge & 6.03 & 61.8 & 5,645 & 920 & 86.11 & AAUJ02000000 [23] \\
\hline
\end{tabular}

which could determine whether pan-genome is open $(\alpha \leq 1)$ or closed $(\alpha>1)$ (where $n$ is the number of new genes, $N$ is the number of genomes, $\mathrm{k}$ is another constant).

\section{Phylogenetic analysis}

Consulting the method of Li et al. [41] and Collins et al. [42], the single copy orthologous gene families (contain one gene from one strain), which were extracted from the genomes of $14 \mathrm{C}$. testosteroni strains and from the genomes of 22 strains of family Comamonadaceae, were used to build phylogenomic trees to present the phylogenetic relationship. The predicted amino acid sequences of each gene family were aligned using Clustal W [43]. The independent alignments were concatenated to form a pseudo amino acid sequence alignment. The result was submitted to MEGA6 [44] to build Neighbor-joining (NJ) trees with p-distance. The bootstrap method of 1,000 bootstrap repetitions was used to assess tree reliability. Average Nucleotide Identity (ANI) analysis was performed among the 14 genomes from different sampling areas using Jspecies1.2.1 [45].

\section{Analysis of important physiological and biochemical characteristics of $11 \mathrm{C}$. testosteroni strains}

Most of physiological and biochemical characteristics were determined using the API 20NE system (bioMe'rieux, Marcyl'Etoile, France), except for the utilization of citrate that was detected using Simmons' citrate assimilation test [46]. For utilization of acetate, testosterone and 4HBA, the strains were cultured in basal medium containing standard minerals based on Stanier et al. [3] and with $0.3 \%$ (wt/vol) sodium acetate trihydrate, $0.2 \%(\mathrm{wt} / \mathrm{vol})$ testosterone and $0.2 \%(\mathrm{wt} / \mathrm{vol}$ ) sodium $4 \mathrm{HBA}$, respectively, and incubated at $28^{\circ} \mathrm{C}$ for 10 days. The Minimum Inhibitory Concentrations (MICs) of $\mathrm{Hg}(\mathrm{II}), \mathrm{Cu}(\mathrm{II})$ and $\mathrm{Zn}$ (II) were detected in CDM solid medium [47] containing increasing concentrations of $\mathrm{HgCl}_{2}, \mathrm{CuSO}_{4} \cdot 5 \mathrm{H}_{2} \mathrm{O}$, and $\mathrm{ZnCl}_{2}$, respectively [48]. Antibiotic susceptibility tests for penicillins (penicillin, prostaphlin and ampicillin), kanamycin, and tetracycline were detected using disk diffusion test on MuellerHinton agar with $10 \mu \mathrm{g}$ penicillin, $1 \mu \mathrm{g}$ prostaphlin, $10 \mu \mathrm{g}$ ampicillin, $30 \mu \mathrm{g}$ kanamycin and $30 \mu \mathrm{g}$ tetracycline disks, respectively (HangZhou Microbial Reagent Co. LTD, China).

\section{Construction of putative metabolic pathways based on the genomic sequences}

The predicted proteins of each genome were submitted to KEGG Automatic Annotation Server (KAAS) [49] to perform KEGG Orthology (KO) functional annotation. The results were then submitted to Mapper of Kyoto Encyclopedia of Genes and Genomes (KEGG) [50] to reconstruct metabolic pathways.

\section{Identification of heavy metal- and drug-resistant genes and virulence factors}

Genes involved in heavy metal- and drug-resistance were identified base on the SEED gene functional classification of the "resistance to antibiotics and toxic compounds" subsystem on RAST server [35-37]. The identified genes were grouped into gene clusters. Orthologous genes from each genome were aligned by Clustal W [43], concatenated, and then submitted to MEGA6 [44] to build NJ trees with p-distance and bootstrap method of 1000 bootstrap repetitions. 
The virulence factors were identified by aligning the predicted protein sequences from the genomes of 14 C. testosteroni strains against the Virulence Factors Data Bases (VFDB) [51] using blastp of NCBI-blast 2.27+ with the standard of E-value $\leq 1 \mathrm{e}-5$, identity $\geq 50 \%$, match $\geq 70 \%$.

\section{Identification of putative genes responsible for the physiological and biochemical characteristics}

Genes for nitrate/nitrite reduction were identified base on the SEED gene functional classification of the "Nitrate and nitrite ammonification" subsystem on RAST server [35-37]. Five gene clusters for steroid degradation that were found in C. testosteroni strain TA441 (GenBank: AB489116, AB040808, AB063482, AB076368, AB186487) [10-15] were searched against each genome sequence using blastn of NCBI-blast2.27+ program [39]. Protein sequences from these 5 gene clusters were also searched against all the predicted proteins in the 22 genomes using blastp. Gene cluster of PCA 4,5-cleavage [20] that is potentially involved in $4 \mathrm{HBA}$ degradation was searched against the predicted proteins of genomes of $C$. testosteroni using blastp. The orthologous genes for steroid degradation, PCA 4,5-cleavage and nitrate/nitrite reduction were used to build evolutionary trees. Amino acid sequences of orthologous genes were aligned by Clustal W [43], concatenated, and submitted to MEGA6 [44] to build NJ trees with p-distance and bootstrap method of 1000 bootstrap repetitions. The correlation value between genotypes and phenotypes is calculated based on the phenotypic results compared with the presence or absence of the putative corresponding genes.

\section{Results}

Genome sequencing and features of $14 \mathrm{C}$. testosteroni strains

Ten genomes of C. testosteroni (strains JC8, JC9, JC12, JC13, JL14, JL40, D4, DS1, DF1 and DF2) were sequenced in this study using Illumina HiSeq2000. After trimming the raw data, we obtained $7,130,708$ to $16,794,780$ paired reads and 147,354 to 383,694 single reads with the average read lengths from $94 \mathrm{bp}$ to $96 \mathrm{bp}$ for each genome. The sequencing depths were from $116.2 x$ to $283.2 x$. The reads of each genome were assembled into 75 to 238 contigs, and the total length of each draft genome was from $5,061,365 \mathrm{bp}$ to $5,956,604 \mathrm{bp}$. The contig N50 was from $98,152 \mathrm{bp}$ to $242,732 \mathrm{bp}$, and the contig N90 was from $18,558 \mathrm{bp}$ to $56,606 \mathrm{bp}$. The details about the sequencing and assembly of each genome are showed in Additional file 3: Table S3.

Features of the ten newly sequenced and four published genomes of C. testosteroni were showed in Table 1. The sizes of $C$. testosteroni genomes are from $5.06 \mathrm{Mb}$ to $6.03 \mathrm{Mb}$, and the $\mathrm{G}+\mathrm{C}$ contents are from $61.1 \%$ to $61.8 \%$. The predicted numbers of open reading frames
(ORFs) are from 4674 to 5645 with the average lengths from $897 \mathrm{bp}$ to $938 \mathrm{bp}$. These coding sequences cover $85 \%$ to $86 \%$ of their genome sequences.

\section{The core- and pan-genomes of $C$. testosteroni}

To determine whether the pan-genome of C. testosteroni is closed or open, the Heap's law [40] was used in our study. As showed in Figure 1A, the medians of new genes $(n)$ and the numbers of genomes $(N)$ are least squares fit of the power law $n=\kappa N^{a}$, and the constant $\alpha$ is $0.639 \pm$ 0.016 . This indicated that C. testosteroni may have an open pan-genome. For the 14 genomes, the core-genome has 3599 gene families, and the pan-genome has 10,165 gene families. The pan-genome size is two times of the average genome size and 2.8 times of the core-genome size. The core-genome accounts for $35 \%$ of the pan-genome and $64.7 \%$ to $77.8 \%$ of each individual genome. In each genome, the unique genes (listed in Additional file 4: Table S4) are from 5 to 888 , accounting for $0.1 \%$ (JC12, JC13) to $15.7 \%$ (KF-1) of its total gene numbers (Figure 1B).

\section{Phylogenetic relationships between $C$. testosteroni and other species in family Comamonadacea and among $C$. testosteroni strains}

To understand the phylogenetic relationship among the $C$. testosteroni strains, a neighbor-joining (NJ) tree based on the core-genome of the $14 \mathrm{C}$. testosteroni strains was built (Figure 2A). The core-genome of the $14 \mathrm{C}$. testosteroni strains contains 3,483 single copy orthologues. As the tree showed, the strains from the same original area are clustered together except for those from Lengshuijiang antimony mine soil. Strains from Lengshuijiang antimony mine (JL14, JL40, and S44) are distributed in different branches. The strain KF-1 is located on a standalone branch.

To understand the phylogenetic relationship between C. testosteroni and other species in family Comamonadacea, we performed phylogenetic analysis among the 14 C. testosteroni strains together with eight more sequenced strains from different species of family Comamonadacea (Additional file 2: Table S2). A NJ tree based on a total of 1,003 single copy orthologous gene families of 22 strains was built (Figure 2B). All the 14 C. testosteroni strains are grouped together. Strain Delftia acidovorans $\mathrm{SPH}-1$, which was classified to genus Comamonas before 1999 [52], showed a closer relationship with strains of $C$. testosteroni than with the other seven species of family Comamonadacea.

\section{The relationship between the genome similarity and the geographic distance}

To understand if there is a distance decay relationship to the genome similarity of this species, we compared the ANIs with the geographic distances among different isolation areas of the C. testosteroni strains. As showed 

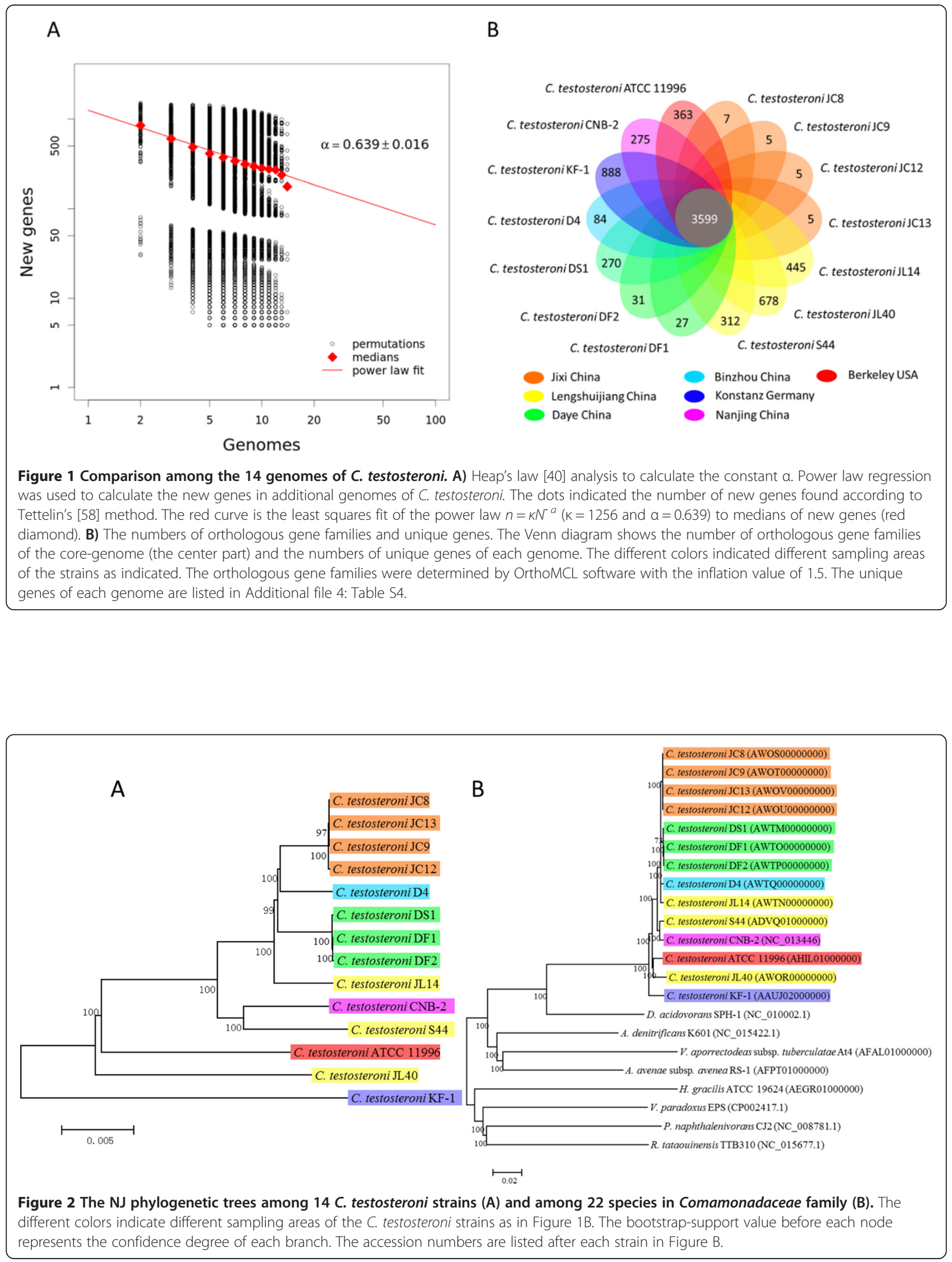
in Figure 3, the ANIs for strains from different continents are obviously smaller than for strains from the same continents (isolation areas inside China). However, there is no clear ANI-distance relationship among the isolation areas inside China $\left(\mathrm{R}^{2}=0.011\right)$ and from different continents $\left(R^{2}=0.3959\right)$.

\section{High correlation between phenotypes and genotypes in} C. testosteroni

In order to establish the relationship between phenotypes and genotypes among the strains of $C$. testosteroni and to provide detailed insights into the genomes of this species, 31 important phenotypes and their related genome features of 11 strains of $C$. testosteroni isolated in our laboratory (S44, JL14, JL40, JC8, JC9, JC12, JC13, DS1, D4, DF1, DF2) were tested and studied. Our results showed a high correlation between the phenotypes and genotypes (Figure 4). First, all the trains showed the ability of nitrate reduction and urea hydrolysis; they can utilize testosterone, adipate, malate, gluconate, acetate, lactate and $4 \mathrm{HBA}$ as their sole carbon source; they could resist penicillin, prostaphlin, ampicillin, $\mathrm{Cu}$ (II) and $\mathrm{Zn}$ (II). In the genomes of these strains, we found genes or complete metabolic pathways for these features. Second, none of the strains showed the ability of tryptophan hydrolysis, glucoside hydrolysis, gelatin hydrolysis, galactoside hydrolysis and glucose acidification; they cannot utilize most carbohydrates such as glucose, arabinose, mannose, mannitol, N-Acetyl-D-glucose and maltose; they could not resist tetracycline. In the genomes of these strains, no corresponding genes of these features could be found. Third, the strains DF1, DF2, DS1, S44, JL14, JL40 are resistant and D4, JC8, JC9, JC12, JC13 are sensitive to mercury. In the genomes of DF1, DF2, DS1, S44, JL14, JL40, the mercury resistance genes could be found, but in the genomes of D4, JC8, JC9, JC12 and JC13, the mercury resistance genes could not be found.

In all, we found that $99.4 \%$ of a total of $31 \times 11$ biophysical and biochemical characters were concordant between phenotypes and genotypes. The only two exclusions were that arginine double hydrolysis test showed positive on strain JC9 and kanamycin resistance test showed positive on strain DS1, but the genes for these metabolisms were not found in their genomes.

\section{Important genotypes of C. testosteroni \\ The conservative gene clusters of nitrate/nitrite reduction \\ founded in all the C. testosteroni genomes and other genomes of Comamonadacea}

The physiological and biochemical tests showed that all the strains of $C$. testosteroni have the ability of nitrate reduction. This phenotype has been found in strains of other species of genus Comamonas [53]. Based on RAST annotation result, we found 12 gene orthologues in the SEED subsystem "Nitrate and nitrite ammonification". These genes are distributed in three gene clusters and some dispersal regions in the genomes of $C$. testosteroni (Additional file 5: Table S5). Importantly, a gene cluster responsible for nitrate and nitrite reduction could be found in all of the 14 C. testosteroni genomes (Figure 5). Similar gene clusters could also be found in all the eight other genomes of Comamonadacea. However, some genes were missed in the cluster, or the gene arrangement was quite different (Figure 5).

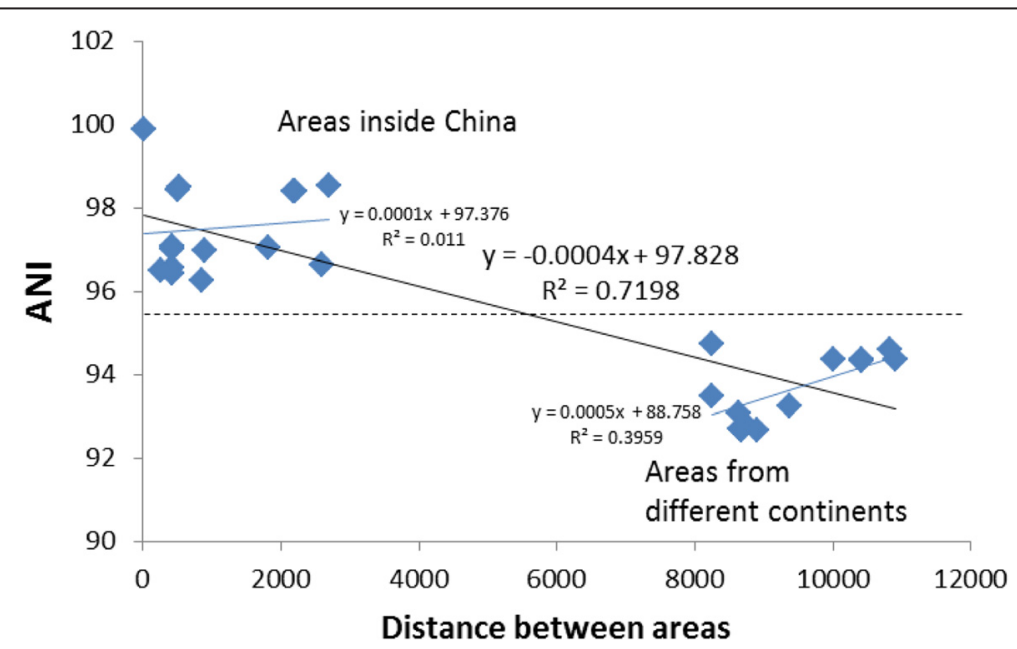

Figure 3 Distance decay analysis using ANIs among C. testosteroni strains from different areas. The $x$ axis is the distance between different areas calculated by latitude and longitude (Additional file 1: Table S1). The $y$ axis is the ANI between the pairs of strains isolated from different areas. Linear regressions were taken between the ANIs and distances, and the R squares were given. The dotted line separates the ANI-distance relations among areas inside China (above) and those among areas from different continents. 


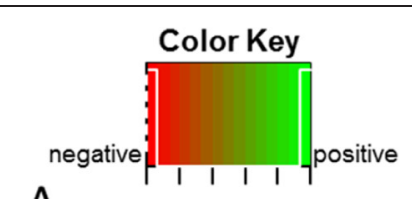

A

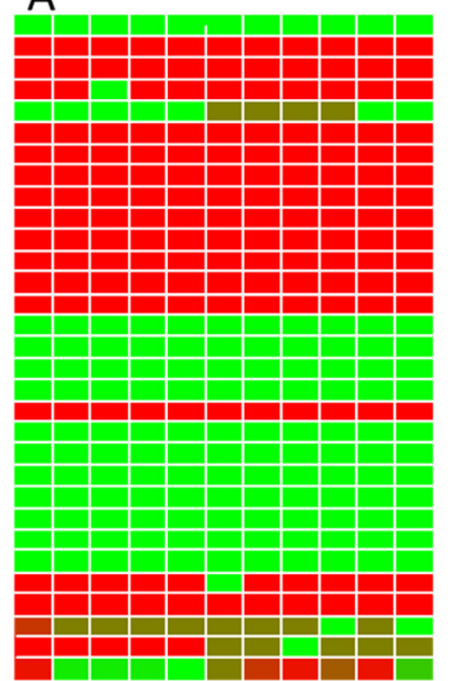

B

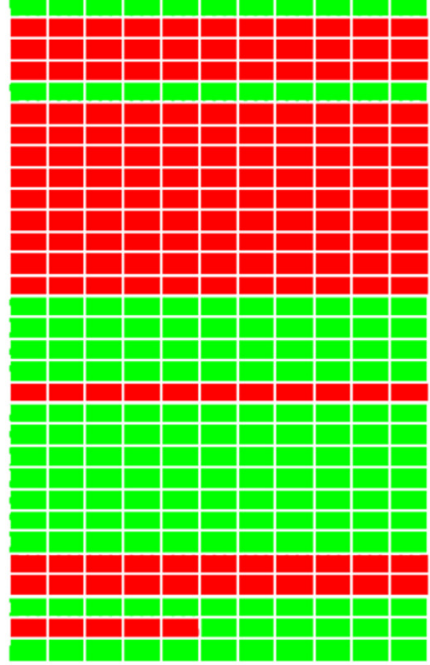

ryption

Glucose acidífication

Arginine dihydrolysis

Urea hydrolysis

Glucoside hydrolysis

Gelatin hydrolysis

Galactoside hydrolysi

Glucose utilization

Arabinose utilization

Mannose utilization

Mannitol utilization

$\mathrm{N}$-acetyl-glucosamine utilization

Maltose utilization

Gluconic acid utilization

Adipate utilization

Malate utilization

Citrate utilization

Phenylacetic acid utilization

Acetate utilization

Lactate utilization

Testosterone utilization

4HBA utilization

Penicillin resistance

Prostaphlin resistance

Ampicillin resistance

Kanamycin resistance

Tetracycline resistance

Copper resistance

Mercury resistance

Zinc resistance

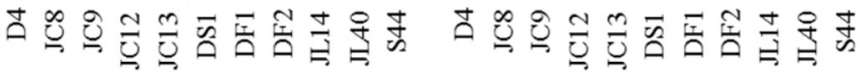

Figure 4 Correlation between genotypes and phenotypes among the 11 C. testosteroni strains. A) The heat map that presents 31 phenotypes of $11 \mathrm{C}$. testosteroni strains. B) The heat map that presents 31 genotypes of $11 \mathrm{C}$. testosteroni strains. The Green/red boxes in the heat map represent positive/negative features of strains. The intermediate color in the row for urea hydrolysis in Figure A means weak positive response, and the intermediate color in the last three rows in Figure A means numerical values.

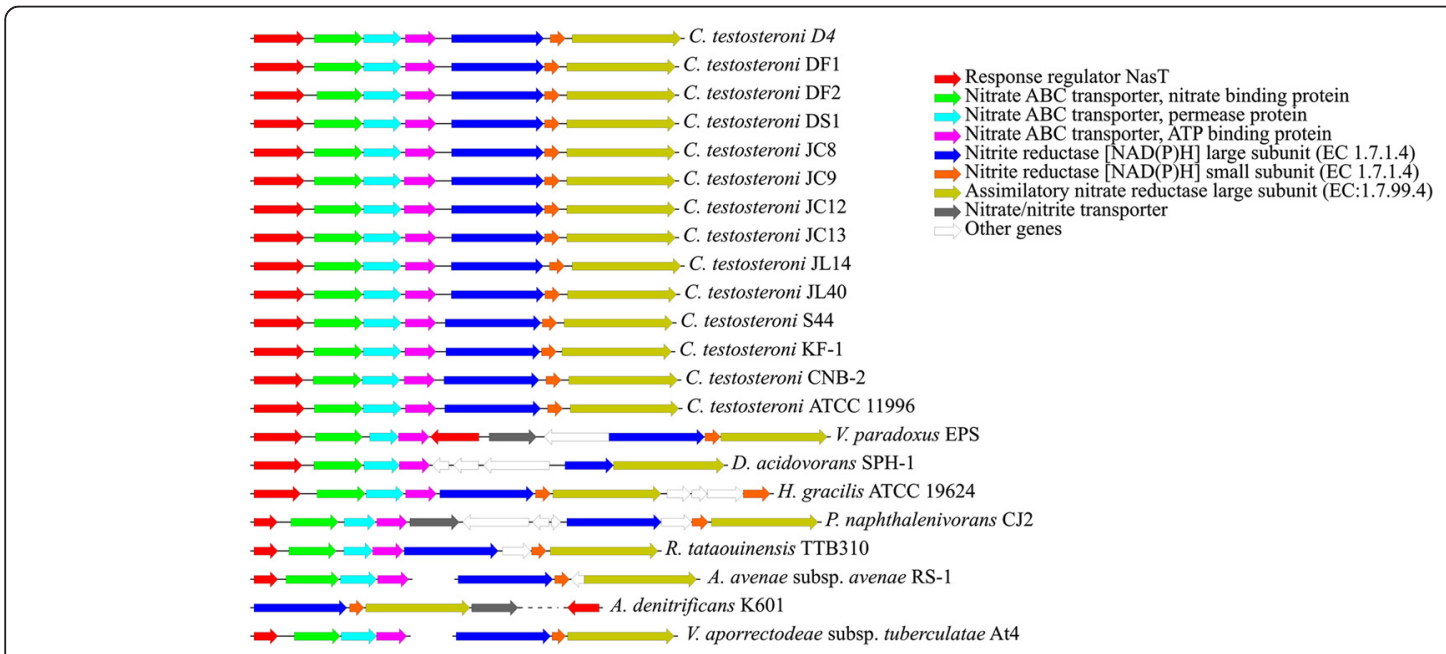

Figure 5 The nitrate/nitrite reduction gene clusters that were shared by all the $C$. testosteroni genomes and the eight other genomes of Comamonadacea. The gene orthologues for different functions are showed in different colors. White arrows indicate genes for other functions that were not correlated with nitrate/nitrite reduction. The breaks in the clusters from A. avenae subsp. avenae RS-1 and V. aporrectodeae subsp. tuberculatae At4 mean that the genes are distributed in different contigs. The dotted line in the cluster from A. denitrificans K601 means that the interval between the genes is very long. 
The key genes for hexose phosphorylation missed in the $C$. testosteroni genomes

Previous studies $[3,5,22]$ and our phenotype test both indicated that strains of $C$. testosteroni cannot use most types of six carbon sugars as their sole carbon sources. To understand the genome bases of this phenotype, we reconstructed the metabolic pathway map of these strains through Encyclopedia of Genes and Genome (KEGG). The metabolic procedures of the carbon sources in our test (except for decanoic acid, testosterone and phenylacetic acid) were drawn in Figure 6. Complete metabolic pathways of adipate, D-gluconate, citrate, malate, acetate and lactate, which can be utilized by these strains, can be found, whereas the phosphorylation steps in the utilization procedure of D-glucose, N-Acetyl-D-glucose, D-mannose and D-mannitol, which cannot be utilized by these strains, cannot be found. These results are consistent with previous reports that the glucokinase and hexokinase were missed [5,22] in the genomes of $C$. testosteroni.

\section{Genomic bases of utilization of steroids and aromatic compounds in C. testosteroni}

Testosterone (a kind of steroids) degradation is the main feature of C. testosteroni, based on which this species was identified and named [1]. We searched the five gene clusters relating to steroid degradation, which were found in C. testosteroni strain TA441 [15], in the 14 genomes of C. testosteroni. As showed in Figure 7, these clusters were distributed in a $105 \mathrm{~Kb}$ region on the genome sequence of the strain CNB-2. Based on the genomic DNA sequences, all the five gene clusters (listed in Additional file 6: Table S6) could be found in each of the C. testosteroni genomes, while based on the predicted protein sequences, the ORF25 was missed in KF-1 and JL40 genomes (Figure 7). However, the ORF25 is similar to the ORF26 (with 65\% identity), and they both showed to have a GGCT-like domain by searching the Conserved Domain Database [54]. Therefore, lacking the ORF25 may not affect the steroid degradation function. We also searched these five gene

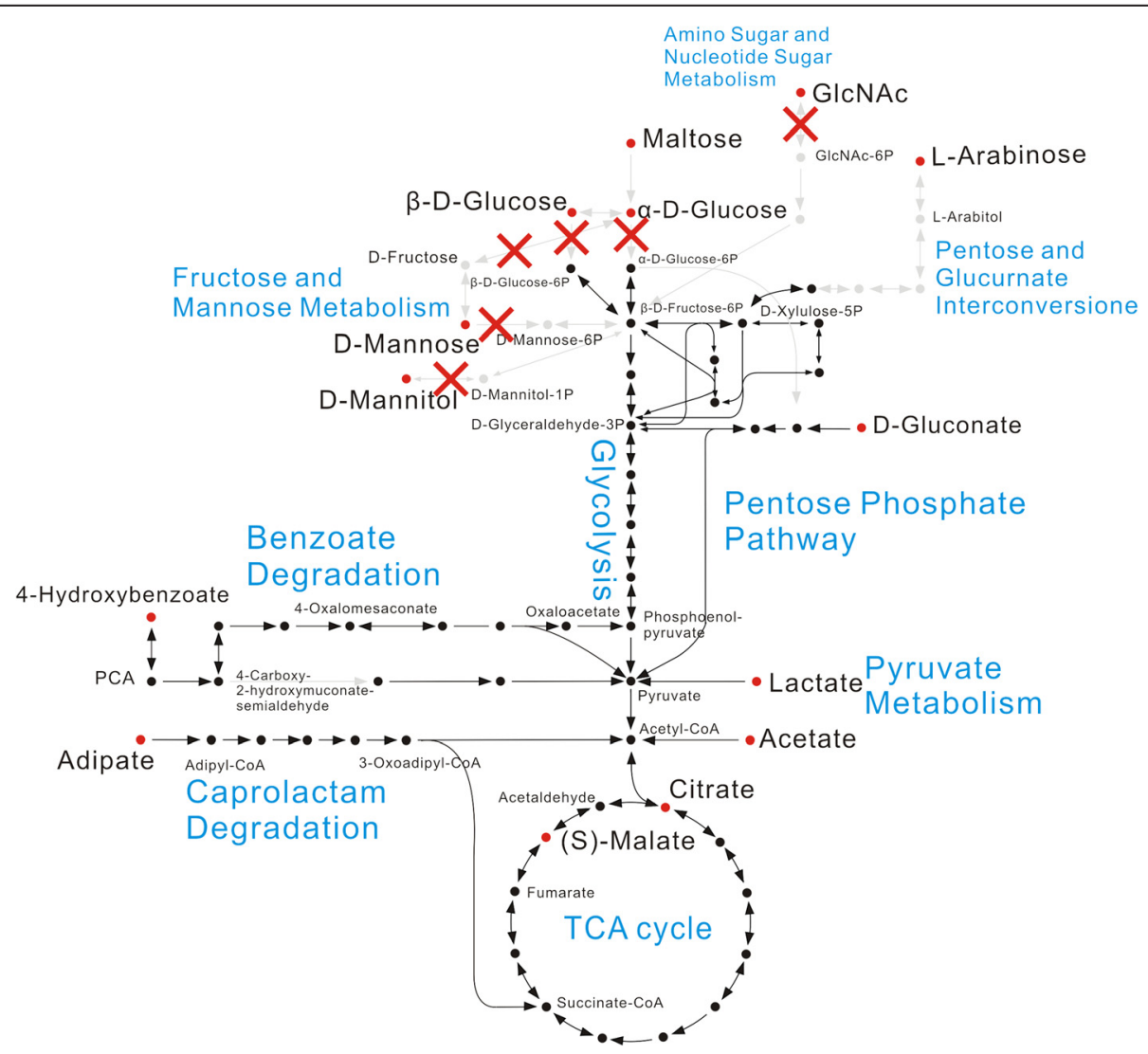

Figure 6 The assimilatory pathway map of D-glucose, maltose, D-mannose, D-mannitol, D-gluconate, L-arabinose, citrate, malate, acetate, lactate, 4HBA, adipate, and $\mathrm{N}$-acetyl-glucosamine in C. testosteroni. Labels in blue indicate different pathways of KEGG pathway map. The red points represent the substrates we tested in physiological and biochemical test. Arrows and points in black mean that the pathway could be found whereas those in grey mean that the pathway cannot be found in the genomes of the $C$. testosteroni strains. The red crosses indicate the lacked phosphorylation steps in the utilization procedure of D-glucose, N-Acetyl-D-glucose, D-mannose and D-mannitol. This pathway map is common for all the strains of C. testosteroni. 


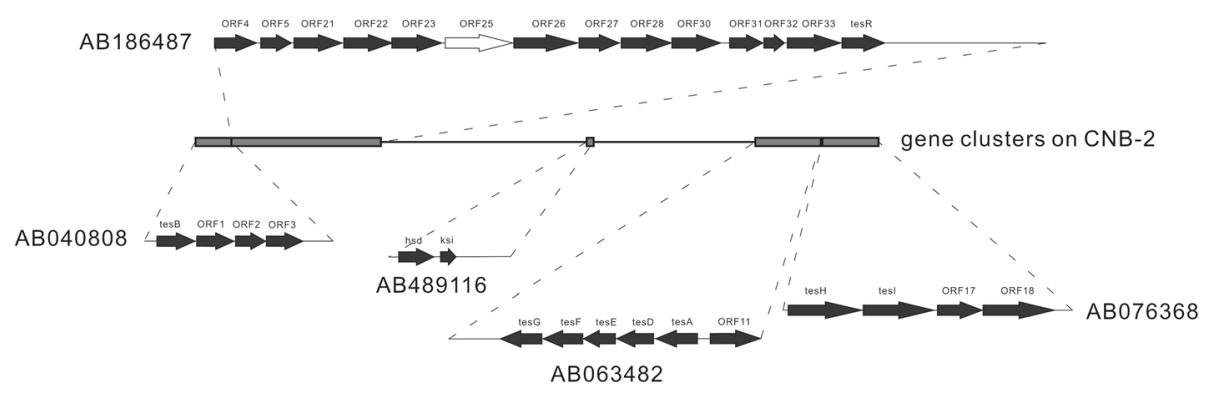

Figure 7 The structure and distribution of the five gene clusters for steroids degradation on the genomes of the $14 \mathrm{C}$. testosteroni strains. The distribution of these clusters on the genome of strain CNB-2 is showed in the middle. The genes in each cluster are showed above and below and marked with GenBank accession number of homologous cluster from C. testosteroni TA441. The black arrows indicate that the genes could be found in all of the strains. The white arrow indicates that the ORF25 is missed in the strain KF-1 and JL40. The genes of these gene clusters from each genome could be viewed in Additional file 6: Table S6.

clusters in other genomes of the family Comamonadacea and could not find any complete one. Only the homologous genes of tesG and tesF could be found (the percent of identity and percent of match are greater than $70 \%$ ).

A previous report indicated that strains of $C$. testosteroni could utilize 4HBA [3]. Our phenotype tests showed that all strains of $C$. testosteroni could use 4HBA as their sole carbon source. We searched the genes for 4HBA degradation using blastp and KEGG annotation tools. The gene cluster which is potentially involved in PCA (protocatechuate) 4,5-cleavage [20], and the gene for transforming 4HBA into PCA were found in the genomes of this species (Figures 6 and 8, Additional file 7: Table S7). This gene cluster was separated into two contigs and part of the ORF that codes for PCA 4,5-dioxygense beta chain was missed in genome sequences of D4, DF1, DF2, DS1, JC8, JC9, JC12, JC13, JL14 and JL40 (Figure 8 ), probably due to the inability of the illumina sequencing method in this region.

\section{The genes for antibiotics and heavy metal resistance}

Our previous study showed that the strain S44 of C. testosteroni has multiple heavy metal resistances [6]. In this study, we found that all strains of $C$. testosteroni can resist $\mathrm{Cu}(\mathrm{II}), \mathrm{Zn}(\mathrm{II})$, penicillin, prostaphlin and ampicillin. Six of them can resist $\mathrm{Hg}$ (II). Based on RAST annotation result, gene clusters and scattered genes relating to heavy metal and medico resistances were found in the genomes of C. testosteroni. Of these gene clusters, 11 were shared in all of the 14 genomes (Additional file 8: Table S8). They included homologous genes for RND transporter families such as Czc family of cobalt-zinc-cadmium RND efflux transporter, Cme family of multidrug resistance RND efflux system and multidrug efflux RND membrane fusion protein $\mathrm{MexC}$, and homologous genes for copper homeostasis such as copper homeostasis protein CutE, copper chaperone and copper-translocation P-type ATPase. Besides, there were many types of gene clusters that were not shared in all of these genomes (Additional file 8:

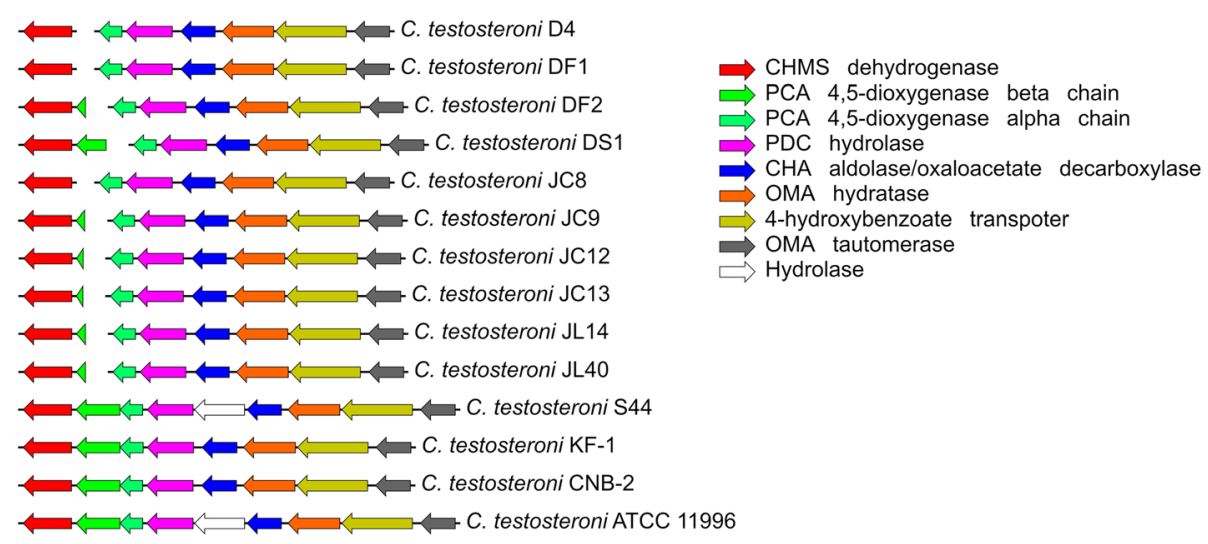

Figure 8 The gene cluster found in the C. testosteroni genomes that is potentially involved in PCA 4,5-cleavage pathway. The genes' functions were annotated according to Ni's report [20] and RAST annotation result. The orthologues for different functions are showed in different colors. The breaks in the cluster mean that the genes are separated in different contigs. The genes of this cluster from each genome could be viewed in Additional file 7: Table S7. 
Table S8). Genes in these clusters included those resistant to mercury, arsenic and chromium. RND efflux systems of cobalt-zinc-cadmium (Czc family) and multidrug were also found. In addition, many scattered genes such as those for penicillins and fosfomycin resistances were found.

Antibiotics and metal resistances are usually co-selected. The main mechanisms of this phenomenon are coresistance and cross-resistance [55]. Co-resistance means that the genes for antibiotics and metal resistances are located in the same genetic element. Cross-resistance means that the different resistant phenotypes are controlled by the same gene or the same group of genes. In the genomes of C. testosteroni, we found that the genes for different resistance functions were usually clustered in accord with co-resistance. For example, a gene for copper binding protein and a gene for $\mathrm{Cu}(\mathrm{I})$ responsive transcriptional regulator are located near some RND efflux Czc family genes (eg. strain D4 Locus Tag: P609_08845 P609_08895 GenBank: AWTQ00000000). Also, the genes for the cross-resistance can be found in these genomes, such as the cobalt-zinccadmium efflux system Czc family [56] and multidrug resistance system [57]. Notably, most of these efflux systems belong to the Resistance-Nodulation-cell Division (RND) family.

\section{The phylogenetic relationships of the genotypes consistent among the strains of $C$. testosteroni}

To analyze the phylogenetic relationships of the genes for nitrate reduction, steroids degradation, PCA 4,5-cleavage and antibiotics and heavy metal resistance that are consistent among the strains of C. testosteroni, we built NJ trees of these genes from shared gene clusters (Figure 9). We found that the p-distance between genes of these genotypes are no greater than 0.05 . In comparison, the p-distance between homologous proteins from different genus are at least greater than 0.148 (Figure 2B). This indicated that the genes of these clusters are highly conserved. Comparing these trees with the NJ tree of coregenome of the $14 \mathrm{C}$. testosteroni strains (Figure 2A), common features on topology were found. All the strains from Jixi are grouped together and all the strains from Daye are grouped together in each tree. Strains from China (JC8, JC9, JC12, JC13, DF1, DF2, DS1, D4) except those from Lengshuijiang are located closely in all of the trees except that of PCA 4,5-cleavage. The strains from Lengshuijiang are distributed in different branches (JL14, JL40, S44).

\section{Virulence factors in C. testosteroni}

In order to identify potential virulence factors (VFs) in the genomes of $C$. testosteroni, we aligned proteins from the 14 genomes against Virulence Factors Data Base (VFDB) [51] using blastp with the standard E-value $\leq 1 \mathrm{e}$ -
5 , identity $\geq 50 \%$, and match $\geq 70 \%$. As result, we identified 24 types of VFs that were involved in 13 functions such as adherence, anti-phagocytosis, invasion, and secretion system. Of them, 11 VFs are owned by all of the strains. These VFs include 2 types of secretion system (Bsa T3SS, xcp secretion system), urease, flagella of invasion, alginate used for anti-phagocytosis, type IV pili for adherence. Comparing the shared VFs between every two strains, we found that the average identity of the orthologous VFs from different combinations is $99 \%$. The gene numbers of all the found VFs are showed in Additional file 9: Table S9.

\section{Discussion}

The concept of pan-genome was first introduced in 2005 [58]. It is the collection of the total genes that could be found in a species. The pan-genome could reflect the gene pool size of a bacterium [59]. In this study, Heap's law [40] analysis showed that the pan-genome of $C$. testosteroni is open. However, there are limitations in this analysis. First, the strains were not randomly sampled. Some genomes are very similar (e.g. JC8, JC9, JC12, JC13), and some genomes are significantly different from the others (e.g. KF-1). Therefore, we could notice a "break" in Figure 1A. Second, because most of the genomic sequences are draft, some genes may be lost in the sequences (e.g. in Figure 8, the gene for PCA 4,5-dioxygenase beta chain is lost in some strains due to interruption in the coding region of this gene). This may result in an underestimated coregenome and an overestimated pan-genome.

According to the natural selection theory, environment could affect organisms' genetic characters. In our study, we found: a) the strains isolated from the same areas (Jixi and Daye) are always clustered together (this indicates the highest similarity), and b) ANIs among strains from different continents are lower than those from the same continents. These results revealed that the genome similarity of most C. testosteroni strains followed a certain degree of distance-similarity decay relationship.

In previous studies, strains of C. testosteroni showed abilities for nitrate reduction, and utilization of testosterone, 4HBA, acetate and lactate, but they cannot utilize glucose and most of the carbohydrates [3]. In this study, we found that most of the above phenotypes of $C$. testosteroni are consistent with previous studies and consistent among all the tested strains of $C$. testosteroni, indicating that these important phenotypes are very stable and common in C. testosteroni, and could be used in the polyphasic taxonomy in identification of this species.

The key step of aromatic compounds degradation is the benzene ring cleavage and the main pathway for this reaction in strains of genus Comamonas is PCA 4,5-cleavage [19]. In previous study, genes or potential genes for PCA 4,5-cleavage were found in many strains of $C$. 


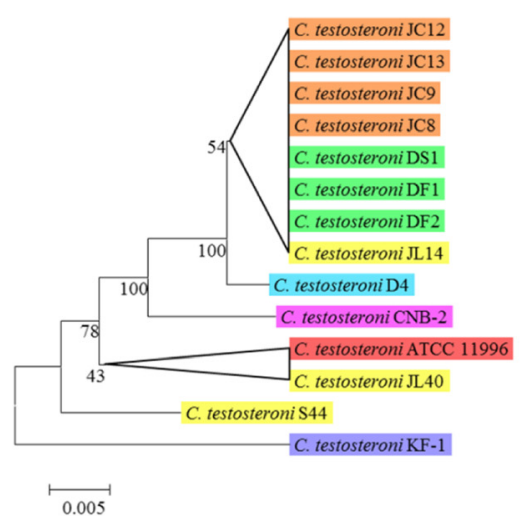

A Nitrate reduction

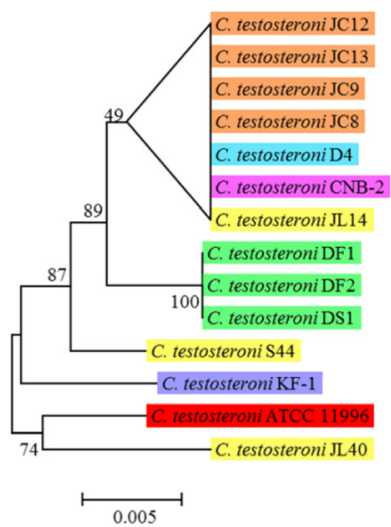

C PCA 4,5-cleavage

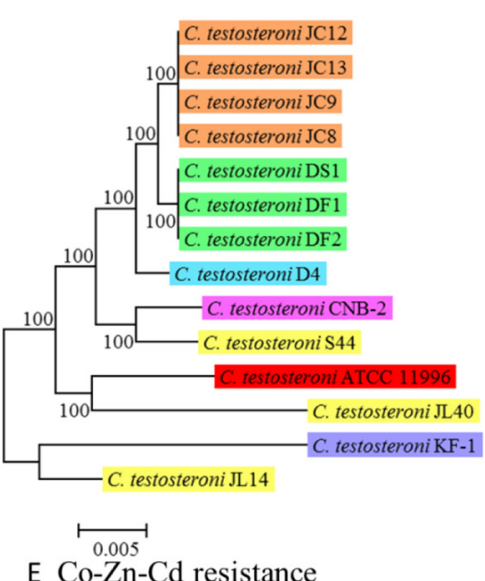

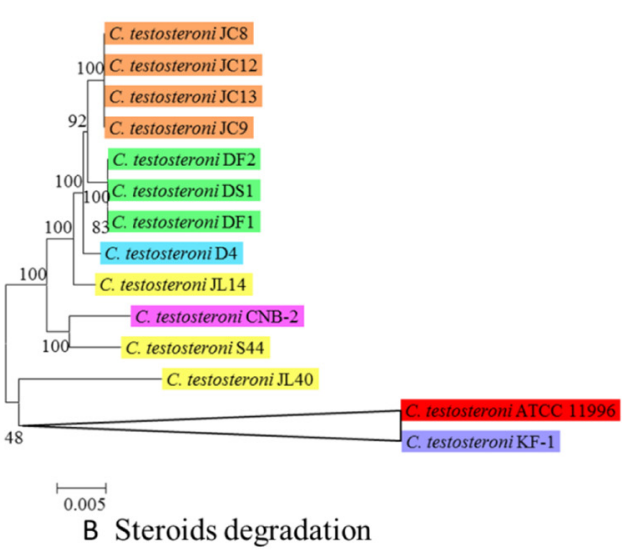
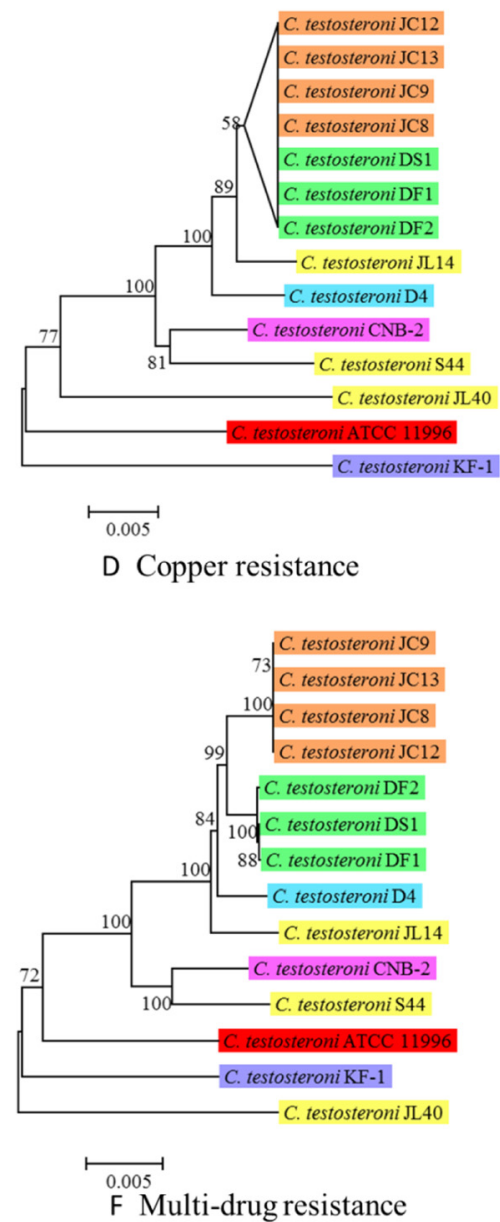

Figure 9 Phylogenetic analyses of the genes for nitrate reduction, steroids degradation and antibiotics and heavy metal resistance that are consistent among the $\mathbf{1 4}$ strains of $\boldsymbol{C}$. testosteroni. A) The NJ tree of the genes for nitrate reduction. B) The NJ tree of the genes for steroids degradation. C) The NJ tree of genes for PCA 4,5-cleavage. D) The NJ tree of the genes for copper resistance. E) The NJ tree of the genes for cobalt-zinc-cadmium resistance. F) The NJ tree of the genes for multidrug resistance. All the genes are from the shared gene clusters. The genes used to build tree A, B and C could be viewed in Additional file 5: Table S5, Additional file 6: Table S6 and Additional file 7: Table S7, respectively. The genes used to build tree $D, E$ and $F$ could be viewed in Additional file 8: Table S8. All trees were built on protein sequences with p-distance. The different colors indicate different sampling areas of the C. testosteroni strains as in Figure 1B. The bootstrap-support value before each node represents the confidence degree of each branch. The branches with the bootstrap-support value less than 60 were collapsed. 
testosteroni such as C. testosteroni BR6020 [60] and C. testosteroni CNB-2 [20]. In this study, potential genes for this function could be found in all of the genomes of C. testosteroni (Additional file 7: Table S7) and the gene cluster for PCA 4,5-cleavage is very conserved among the C. testosteroni strains (Figure 9C). This indicated that the strains of $C$. testosteroni would have potential abilities to degrade various aromatic compounds.

Ma et al. [5] built a main metabolic pathway map of C. testosteroni CNB-2. They found that the glycolysis is incomplete due to lack of the hexokinase and glucokinase genes so that the strain cannot utilize most types of sugars. Studies on the genomes of $C$. testosteroni strains ATCC 11996 [22] and KF-1 [23] showed the same results. We built metabolic pathway maps of 14 strains of C. testosteroni (including above strains) and showed that all genes for hexose phosphorylation were missed in all genomes of this species (Figure 6). This result effectively supports the previous studies and indicates that lack of these genes should be a common genome feature of $C$. testosteroni.

Comparison between the phylogenomic tree of $C$. testosteroni (Figure 2A) and the phylogenetic trees of the genes from the gene clusters for nitrate/nitrite reduction, steroids degradation, antibiotics and heavy metal resistance (Figure 9A, B, D, E and F) revealed that the gene clusters for these functions are conserved and their evolutions are consistent with the evolution of the core-genome. This indicated that the shared gene clusters for these functions are inherent in the genomes of $C$. testosteroni, and they may have suffered little natural selection pressure during the evolutionary process of $C$. testosteroni.

As an environmental bacterium, C. testosteroni is often considered to be nonpathogenic. However, according to the survey by Farshad et al. [61], up to 2012, there were 35 reported cases of human infection by this bacterium. C. testosteroni infected central nervous system [62], blood $[63,64]$, mitral valve [65], subcutaneous tissue [64], eye [66], abdominal cavity [67] and urinary tract [67], that caused purulent meningitis, bacteremia, cellulitis, infectious endocarditis, post-operative endophthalmitis and other diseases. Nevertheless, few molecular biological investigations were taken on the pathogenicity of C. testosteroni. In this study, 24 types of VFs were found in the genomes of $C$. testosteroni with high protein-to-protein identify $(\geq 50 \%)$ and match (match $\geq 70 \%$ ). Further, we found that the shared VFs among the C. testosteroni are highly conserved. This result proposed the molecular biological basis of the potential pathogenicity of this bacterium.

Genotype determines phenotype. Jung et al. [68] found many genotypes relating to antibiotic resistance, oxidative stress, motility, and pectin metabolism in Alishewanella species, and confirmed the phenotypes of them. Ma et al. [5] examined the ability of the utilization of many sugars of $C$. testosteroni $\mathrm{CNB}-2$ and confirmed the genome features that support these phenotypes. However, such a study that focuses on all the main recognition properties and their genome bases on an environmental bacterium is rare. In this study, we found a high correlation between phenotypes and genotypes of this species. The related genes may be useful to study the molecular mechanisms of C. testosteroni.

\section{Conclusions}

In conclusion, we generated the sequences of 10 genomes of $C$. testosteroni and performed comparative genomics analysis among the available genomes of this bacterium. We found that the pan-genome of $C$. testosteroni may be open. Physiological and biochemical investigation showed that $C$. testosteroni has the main properties of nitrate reduction, ability of utilizing testosterone, 4HBA, acetate and lactate, and disability of utilizing glucose and most carbohydrates. Genomic analysis revealed the molecular biological bases of these phenotypes. The phenotypes and genotypes of these features could be used in polyphasic taxonomy and molecular identification of this species. This study is the first comprehensive genomic analysis for C. testosteroni and provides information for better understanding this bacterial species at genomic level. Importantly, this study focused on the analysis of potential genetic determinants for the typical characters, and found the high correlation between the phenotypes and their corresponding genotypes (e.g. genes).

\section{Additional files}

\begin{abstract}
Additional file 1: Table S1. The sampling areas of the Comamonas testosteroni strains.

Additional file 2: Table S2. Genomes of the other species from the family Comamonadacea that are used in this study.

Additional file 3: Table S3. Sequencing results of Comamonas testosteroni.

Additional file 4: Table S4. The unique genes of each C. testosteroni strains that are grouped by OrthoMCL software with inflation value of 1.5.

Additional file 5: Table S5. The gene clusters and dispersed genes for nitrate/nitrite reduction in the C. testosteroni strains.

Additional file 6: Table S6. The gene clusters for steroids degradation in the C. testosteroni strains.

Additional file 7: Table S7. The gene cluster that is potentially involved in PCA 4,5-cleavage pathway in the C. testosteroni strains.

Additional file 8: Table S8. The gene clusters and dispersed genes for metal and medico resistance found in C. testosteroni strains.

Additional file 9: Table S9. Numbers of VFs that are found in genomes of the C. testosteroni strains.
\end{abstract}

Competing interests

The authors declare that they have no competing interests.

Authors' contributions

LL carried out the data analysis and elaborated this manuscript. WZ and ZC detected the physiological and biochemical characteristics and heavy metal 
resistance of the strains. BX detected the antibiotics resistance of the strains. $M L$ and $G W$ designed the project, supervised this work, and finalized this manuscript. All the authors read and approved the final manuscript.

\section{Availability of supporting data}

The data sets supporting the results of this article are available in the additional files and in the RAST (Prokaryotic Genome Annotation Server, http://rast.nmpdr.org) with User ID: C_t_visitor and Password: testosteroni.

\section{Acknowledgement}

This work was supported by the National High Technology Research and Development Program of China (2012AA101402) and the National Natura Science Foundation of China (31170106).

\section{Received: 30 September 2014 Accepted: 3 February 2015}

\section{Published online: 21 February 2015}

\section{References}

1. Marcus Pl, Talalay P. Induction and purification of alpha- and beta-hydroxysteroid dehydrogenases. J Biol Chem. 1956;218:661-74.

2. Tamaoka J, Ha D-M, Komagata K. Reclassification of Pseudomonas acidovorans den Dooren de Jong 1926 and Pseudomonas testosteroni Marcus and Talalay 1956 as Comamonas acidovorans comb. nov. and Comamonas testosteron comb. nov., with an Emended Description of the Genus Comamonas. Int J Syst Bacteriol. 1987;1987:8

3. Stanier RY, Palleroni NJ, Doudoroff M. The aerobic pseudomonads: a taxonomic study. J Gen Microbiol. 1966;43:159-271.

4. Boon N, Goris J, De Vos P, Verstraete W, Top EM. Bioaugmentation of activated sludge by an indigenous 3-chloroaniline-degrading Comamonas testosteroni strain, I2gfp. Appl Environ Microbiol. 2000;66:2906-13.

5. Ma YF, Zhang Y, Zhang JY, Chen DW, Zhu Y, Zheng H, et al. The complete genome of Comamonas testosteroni reveals its genetic adaptations to changing environments. Appl Environ Microbiol. 2009;75:6812-9.

6. Xiong J, Li D, Li H, He M, Miller SJ, Yu L, et al. Genome analysis and characterization of zinc efflux systems of a highly zinc-resistant bacterium, Comamonas testosteroni S44. Res Microbiol. 2011:162:671-9.

7. Locher HH, Leisinger T, Cook AM. Degradation of p-toluenesulphonic acid via sidechain oxidation, desulphonation and meta ring cleavage in Pseudomonas (Comamonas) testosteroni T-2. J Gen Microbiol. 1989;135:1969-78.

8. Schleheck D, Knepper TP, Fischer K, Cook AM. Mineralization of individual congeners of linear alkylbenzenesulfonate by defined pairs of heterotrophic bacteria. Appl Environ Microbiol. 2004;70:4053-63.

9. Liu L, Jiang CY, Liu XY, Wu JF, Han JG, Liu SJ. Plant-microbe association for rhizoremediation of chloronitroaromatic pollutants with Comamonas sp. strain CNB-1. Environ Microbiol. 2007:9:465-73.

10. Horinouchi M, Kurita T, Yamamoto T, Hatori E, Hayashi T, Kudo T. Steroid degradation gene cluster of Comamonas testosteroni consisting of 18 putative genes from meta-cleavage enzyme gene tes $B$ to regulator gene tesR. Biochem Biophys Res Commun. 2004:324:597-604.

11. Horinouchi M, Kurita T, Hayashi T, Kudo T. Steroid degradation genes in Comamonas testosteroni TA441: Isolation of genes encoding a Delta4(5)isomerase and 3alpha- and 3beta-dehydrogenases and evidence for a $100 \mathrm{~kb}$ steroid degradation gene hot spot. J Steroid Biochem Mol Biol. 2010;122:253-63.

12. Horinouchi M, Hayashi T, Yamamoto T, Kudo T. A new bacterial steroid degradation gene cluster in Comamonas testosteroni TA441 which consists of aromatic-compound degradation genes for seco-steroids and 3-ketosteroid dehydrogenase genes. Appl Environ Microbiol. 2003;69:4421-30.

13. Horinouchi M, Yamamoto T, Taguchi K, Arai H, Kudo T. Meta-cleavage enzyme gene tesB is necessary for testosterone degradation in Comamonas testosteroni TA441. Microbiology. 2001;147:3367-75.

14. Horinouchi M, Hayashi T, Koshino H, Yamamoto T, Kudo T. Gene encoding the hydrolase for the product of the meta-cleavage reaction in testosterone degradation by Comamonas testosteroni. Appl Environ Microbiol. 2003:69:2139-52.

15. Horinouchi M, Hayashi T, Kudo T. Steroid degradation in Comamonas testosteroni. J Steroid Biochem Mol Biol. 2012:129:4-14.

16. Wang YZ, Zhou Y, Zylstra GJ. Molecular analysis of isophthalate and terephthalate degradation by Comamonas testosteroni YZW-D. Environ Health Perspect. 1995;103 Suppl 5:9-12.
17. Arai H, Ohishi T, Chang MY, Kudo T. Arrangement and regulation of the genes for meta-pathway enzymes required for degradation of phenol in Comamonas testosteroni TA441. Microbiology. 2000;146(Pt 7):1707-15.

18. Arai H, Akahira S, Ohishi T, Maeda M, Kudo T. Adaptation of Comamonas testosteroni TA441 to utilize phenol: organization and regulation of the genes involved in phenol degradation. Microbiology. 1998;144(Pt 10):2895-903.

19. Kamimura N, Aoyama T, Yoshida R, Takahashi K, Kasai D, Abe T, et al. Characterization of the Protocatechuate 4,5-Cleavage Pathway Operon in Comamonas sp Strain E6 and Discovery of a Novel Pathway Gene. Appl Environ Microbiol. 2010;76:8093-101.

20. Ni B, Zhang Y, Chen DW, Wang BJ, Liu SJ. Assimilation of aromatic compounds by Comamonas testosteroni: characterization and spreadability of protocatechuate 4,5-cleavage pathway in bacteria. Appl Microbiol Biotechnol. 2013;97:6031-41.

21. Zhang Y, Ma YF, Qi SW, Meng B, Chaudhry MT, Liu SQ, et al. Responses to arsenate stress by Comamonas sp. strain CNB-1 at genetic and proteomic levels. Microbiology. 2007;153:3713-21.

22. Gong W, Kisiela M, Schilhabel MB, Xiong G, Maser E. Genome sequence of Comamonas testosteroni ATCC 11996, a representative strain involved in steroid degradation. J Bacteriol. 2012;194:1633-4.

23. Weiss M, Kesberg Al, Labutti KM, Pitluck S, Bruce D, Hauser L, et al. Permanent draft genome sequence of Comamonas testosteroni KF-1. Stand Genomic Sci. 2013;8:239-54.

24. Li J, Wang Q, Zhang SZ, Qin D, Wang GJ. Phylogenetic and genome analyses of antimony-oxidizing bacteria isolated from antimony mined soil. Int Biodeter Biodegr. 2013;76:76-80

25. Shi Z, Cao Z, Qin D, Zhu W, Wang Q, Li M, et al. Correlation models between environmental factors and bacterial resistance to antimony and copper. PLoS One. 2013;8:e78533.

26. Luo R, Liu B, Xie Y, Li Z, Huang W, Yuan J, et al. SOAPdenovo2: an empirically improved memory-efficient short-read de novo assembler. GigaScience. 2012;1:18

27. Shotgun Assembly Sequences: genome (WGS) [http://www.ncbi.nlm.nih. gov/Traces/wgs/]

28. Xie GL, Zhang GQ, Liu H, Lou MM, Tian WX, Li B, et al. Genome sequence of the rice-pathogenic bacterium Acidovorax avenae subsp. avenae RS-1. J Bacteriol. 2011;193:5013-4.

29. Oosterkamp MJ, Veuskens T, Plugge CM, Langenhoff AA, Gerritse J, van Berkel WJ, et al. Genome sequences of Alicycliphilus denitrificans strains BC and K601T. J Bacteriol. 2011;193:5028-9.

30. Yagi JM, Sims D, Brettin T, Bruce D, Madsen EL. The genome of Polaromonas naphthalenivorans strain CJ2, isolated from coal tar-contaminated sediment, reveals physiological and metabolic versatility and evolution through extensive horizontal gene transfer. Environ Microbiol. 2009;11:2253-70.

31. De Luca G, Barakat M, Ortet P, Fochesato S, Jourlin-Castelli C, Ansaldi M, et al. The cyst-dividing bacterium Ramlibacter tataouinensis TTB310 genome reveals a well-stocked toolbox for adaptation to a desert environment PLoS One. 2011;6:e23784

32. Chen S, Beeby M, Murphy GE, Leadbetter JR, Hendrixson DR, Briegel A, et al. Structural diversity of bacterial flagellar motors. EMBO J. 2011;30:2972-81.

33. Han JI, Spain JC, Leadbetter JR, Ovchinnikova G, Goodwin LA, Han CS, et al. Genome of the Root-Associated Plant Growth-Promoting Bacterium Variovorax paradoxus Strain EPS. Genome Announcements. 2013;1:e00843-13.

34. Kjeldsen KU, Bataillon T, Pinel N, De Mita S, Lund MB, Panitz F, et al. Purifying selection and molecular adaptation in the genome of Verminephrobacter, the heritable symbiotic bacteria of earthworms. Genome Biol Evol. 2012:4:307-15.

35. Aziz RK, Bartels D, Best AA, DeJongh M, Disz T, Edwards RA, et al. The RAS Server: rapid annotations using subsystems technology. BMC Genomics. 2008;9:75.

36. Overbeek R, Olson R, Pusch GD, Olsen GJ, Davis JJ, Disz T, et al. The SEED and the Rapid Annotation of microbial genomes using Subsystems Technology (RAST). Nucleic Acids Res. 2014:42:D206-214.

37. Prokaryotic Genome Annotation Server (RAST) [http://rast.nmpdr.org]

38. Li L, Stoeckert Jr CJ, Roos DS. OrthoMCL: identification of ortholog groups for eukaryotic genomes. Genome Res. 2003;13:2178-89.

39. Camacho C, Coulouris G, Avagyan V, Ma N, Papadopoulos J, Bealer K, et al. BLAST+: architecture and applications. BMC bioinformatics. 2009;10:421.

40. Tettelin H, Riley D, Cattuto C, Medini D. Comparative genomics: the bacterial pan-genome. Curr Opin Microbiol. 2008;11:472-7. 
41. Li X, Hu Y, Gong J, Zhang L, Wang G. Comparative genome characterization of Achromobacter members reveals potential genetic determinants facilitating the adaptation to a pathogenic lifestyle. Appl Microbiol Biotechnol. 2013;97:6413-25.

42. Collins RE, Higgs PG. Testing the Infinitely Many Genes Model for the Evolution of the Bacterial Core Genome and Pangenome. Mol Biol Evol. 2012;29:3413-25

43. Thompson JD, Higgins DG, Gibson TJ. CLUSTAL W: improving the sensitivity of progressive multiple sequence alignment through sequence weighting, position-specific gap penalties and weight matrix choice. Nucleic Acids Res. 1994;22:4673-80

44. Tamura K, Peterson D, Peterson N, Stecher G, Nei M, Kumar S. MEGA5: molecular evolutionary genetics analysis using maximum likelihood, evolutionary distance, and maximum parsimony methods. Mol Biol Evol. 2011;28:2731-9.

45. Richter M, Rossello-Mora R. Shifting the genomic gold standard for the prokaryotic species definition. Proc Natl Acad Sci U S A. 2009;106:19126-31.

46. Simmons JS. A Culture Medium for Differentiating Organisms of Typhoid-Colon Aerogenes Groups and for Isolation of Certain Fungi: With Colored Plate. J Infect Dis. 1926;39:6.

47. Weeger W, Lievremont D, Perret M, Lagarde F, Hubert JC, Leroy M, et al. Oxidation of arsenite to arsenate by a bacterium isolated from an aquatic environment. Biometals: an international journal on the role of metal ions in biology, biochemistry, and medicine. 1999;12:141-9.

48. Cai L, Liu G, Rensing C, Wang G. Genes involved in arsenic transformation and resistance associated with different levels of arsenic-contaminated soils. BMC Microbiol. 2009;9:4

49. Moriya Y, Itoh M, Okuda S, Yoshizawa AC, Kanehisa M. KAAS: an automatic genome annotation and pathway reconstruction server. Nucleic Acids Res. 2007;35:W182-185.

50. Kanehisa M, Goto S. KEGG: kyoto encyclopedia of genes and genomes. Nucleic Acids Res. 2000;28:27-30.

51. Chen L, Xiong Z, Sun L, Yang J, Jin Q. VFDB 2012 update: toward the genetic diversity and molecular evolution of bacterial virulence factors. Nucleic Acids Res. 2012;40:D641-645.

52. Wen A, Fegan M, Hayward C, Chakraborty S, Sly LI. Phylogenetic relationships among members of the Comamonadaceae, and description of Delftia acidovorans (den Dooren de Jong 1926 and Tamaoka et al. 1987) gen. nov., comb. nov. Int J Syst Bacteriol. 1999;2:567-76. 49 Pt.

53. Wauters G, De Baere T, Willems A, Falsen E, Vaneechoutte M. Description of Comamonas aquatica comb. nov. and Comamonas kerstersii sp. nov. for two subgroups of Comamonas terrigena and emended description of Comamonas terrigena. Int J Syst Evol Microbiol. 2003;53:859-62.

54. Marchler-Bauer A, Lu S, Anderson JB, Chitsaz F, Derbyshire MK, DeWeese-Scott C, et al. CDD: a Conserved Domain Database for the functional annotation of proteins. Nucleic Acids Res. 2011;39:D225-229.

55. Baker-Austin C, Wright MS, Stepanauskas R, McArthur JV. Co-selection of antibiotic and metal resistance. Trends Microbiol. 2006;14:176-82.

56. Silver S, Phung LT. Bacterial heavy metal resistance: new surprises. Annu Rev Microbiol. 1996;50:753-89.

57. Zgurskaya HI, Nikaido H. Multidrug resistance mechanisms: drug efflux across two membranes. Mol Microbiol. 2000;37:219-25.

58. Tettelin H, Masignani V, Cieslewicz MJ, Donati C, Medini D, Ward NL, et al. Genome analysis of multiple pathogenic isolates of Streptococcus agalactiae: implications for the microbial "pan-genome". Proc Natl Acad Sci U S A. 2005;102:13950-5.

59. Park J, Zhang Y, Buboltz AM, Zhang X, Schuster SC, Ahuja U, et al. Comparative genomics of the classical Bordetella subspecies: the evolution and exchange of virulence-associated diversity amongst closely related pathogens. BMC Genomics. 2012;13:545.

60. Providenti MA, Mampel J, MacSween S, Cook AM, Wyndham RC Comamonas testosteroni BR6020 possesses a single genetic locus for extradiol cleavage of protocatechuate. Microbiology. 2001;147:2157-67.

61. Farshad S, Norouzi F, Aminshahidi M, Heidari B, Alborzi A. Two cases of bacteremia due to an unusual pathogen, Comamonas testosteroni in Iran and a review literature. J Infect Dev Ctries. 2012;6:521-5.

62. Arda B, Aydemir S, Yamazhan T, Hassan A, Tunger A, Serter D. Comamonas testosteroni meningitis in a patient with recurrent cholesteatoma. APMIS: acta pathologica, microbiologica, et immunologica Scandinavica. 2003:111:474-6.
63. Nseir W, Khateeb J, Awawdeh M, Ghali M. Catheter-related bacteremia caused by Comamonas testosteroni in a hemodialysis patient. Hemodialysis international International Symposium on Home Hemodialysis. 2011;15:293-6.

64. Tsui TL, Tsao SM, Liu KS, Chen TY, Wang YL, Teng YH, et al. Comamonas testosteroni infection in Taiwan: Reported two cases and literature review. Journal of microbiology, immunology, and infection = Wei mian yu gan ran za zhi. 2011;44:67-71.

65. Cooper GR, Staples ED, Iczkowski KA, Clancy CJ. Comamonas (Pseudomonas) testosteroni endocarditis. Cardiovascular pathology: the official journal of the Society for Cardiovascular Pathology. 2005;14:145-9

66. Reddy AK, Murthy SI, Jalali S, Gopinathan U. Post-operative endophthalmitis due to an unusual pathogen, Comamonas testosteroni. J Med Microbiol. 2009:58:374-5.

67. Barbaro DJ, Mackowiak PA, Barth SS, Southern Jr PM. Pseudomonas testosteroni infections: eighteen recent cases and a review of the literature. Rev Infect Dis. 1987:9:124-9.

68. Jung J, Park W. Comparative genomic and transcriptomic analyses reveal habitat differentiation and different transcriptional responses during pectin metabolism in Alishewanella species. Appl Environ Microbiol. 2013;79:6351-61.

\section{Submit your next manuscript to BioMed Central and take full advantage of:}

- Convenient online submission

- Thorough peer review

- No space constraints or color figure charges

- Immediate publication on acceptance

- Inclusion in PubMed, CAS, Scopus and Google Scholar

- Research which is freely available for redistribution 